\title{
mTOR-targeted cancer therapy: great target but disappointing clinical outcomes, why?
}

\author{
Shi-Yong Sun $(\bowtie)$ \\ Department of Hematology and Medical Oncology, Emory University School of Medicine and Winship Cancer Institute, Atlanta, GA 30322, \\ $U S A$
}

(C) The Author(s) 2020. This article is published with open access at link.springer.com and journal.hep.com.cn

\begin{abstract}
The mammalian target of rapamycin (mTOR) critically regulates several essential biological functions, such as cell growth, metabolism, survival, and immune response by forming two important complexes, namely, mTOR complex 1 (mTORC1) and complex 2 (mTORC2). mTOR signaling is often dysregulated in cancers and has been considered an attractive cancer therapeutic target. Great efforts have been made to develop efficacious mTOR inhibitors, particularly mTOR kinase inhibitors, which suppress mTORC1 and mTORC2; however, major success has not been achieved. With the strong scientific rationale, the intriguing question is why cancers are insensitive or not responsive to mTOR-targeted cancer therapy in clinics. Beyond early findings on induced activation of PI3K/Akt, MEK/ERK, and Mnk/eIF4E survival signaling pathways that compromise the efficacy of rapalog-based cancer therapy, recent findings on the essential role of GSK3 in mediating cancer cell response to mTOR inhibitors and mTORC1 inhibition-induced upregulation of PD-L1 in cancer cells may provide some explanations. These new findings may also offer us the opportunity to rationally utilize mTOR inhibitors in cancer therapy. Further elucidation of the biology of complicated mTOR networks may bring us the hope to develop effective therapeutic strategies with mTOR inhibitors against cancer.
\end{abstract}

Keywords mTOR; cancer therapy; resistance; GSK3; protein degradation; E3 ubiquitin ligase; PD-L1

\section{Background}

The mammalian target of rapamycin (mTOR) and its mediated signaling pathways are critical for maintaining cell homeostasis through regulation of various biological functions, such as cell growth, metabolism, survival, and immune response. These functions are regulated by mTOR, a serine-threonine kinase, primarily through forming two distinct complexes, namely, mTOR complex 1 (mTORC1) and mTOR complex 2 (mTORC2) [1-3]. Determination of mTOR kinase substrate specificity is dependent on which partner protein it interacts with. mTORC 1 is composed of mTOR and four other associated proteins such as raptor, mLST8, PRAS40, and DEPTOR; signaling of mTORC1 is crucial for regulating capdependent translation initiation, an essential process for synthesis of many oncogenic proteins, such as cyclin D1,

Received May 6, 2020; accepted June 12, 2020

Correspondence: Shi-Yong Sun, ssun@emory.edu
c-Myc, Mcl-1, and Snail, through phosphorylating p70 ribosomal protein S6 kinase (p70S6K) and eukaryotic translation initiation factor 4E (eIF4E) binding protein 1 (4E-BP1). mTORC2 contains mTOR, rictor, mLST8, DEPTOR, mSin1, and protor and phosphorylates Akt, serum and glucocorticoid-inducible kinase (SGK), and protein kinase C (PKC) [2-4] (Fig. 1). The biological functions of mTORC2, particularly those related to regulation of oncogenesis other than its regulation of cytoskeleton and cell survival, have not been fully understood in comparison with mTORC1 [2], although mTORC2 is involved in the positive regulation of cancer development [5-7]. At present, limited information is known about the upstream regulators of the MTORC2 axis; meanwhile, mTORC1 serves as a convergence point of phosphoinositide 3-kinase (PI3K)/Akt and mitogen-activated protein kinase (MAPK)/MEK/ERK signaling pathways, which are often hyperactivated in many types of cancers [8] (Fig. 1). Nonetheless, the mTOR axis is dysregulated in cancers and thus has emerged as an attractive cancer therapeutic target [9].

Rapamycin and its analogs (rapalogs) are specific 


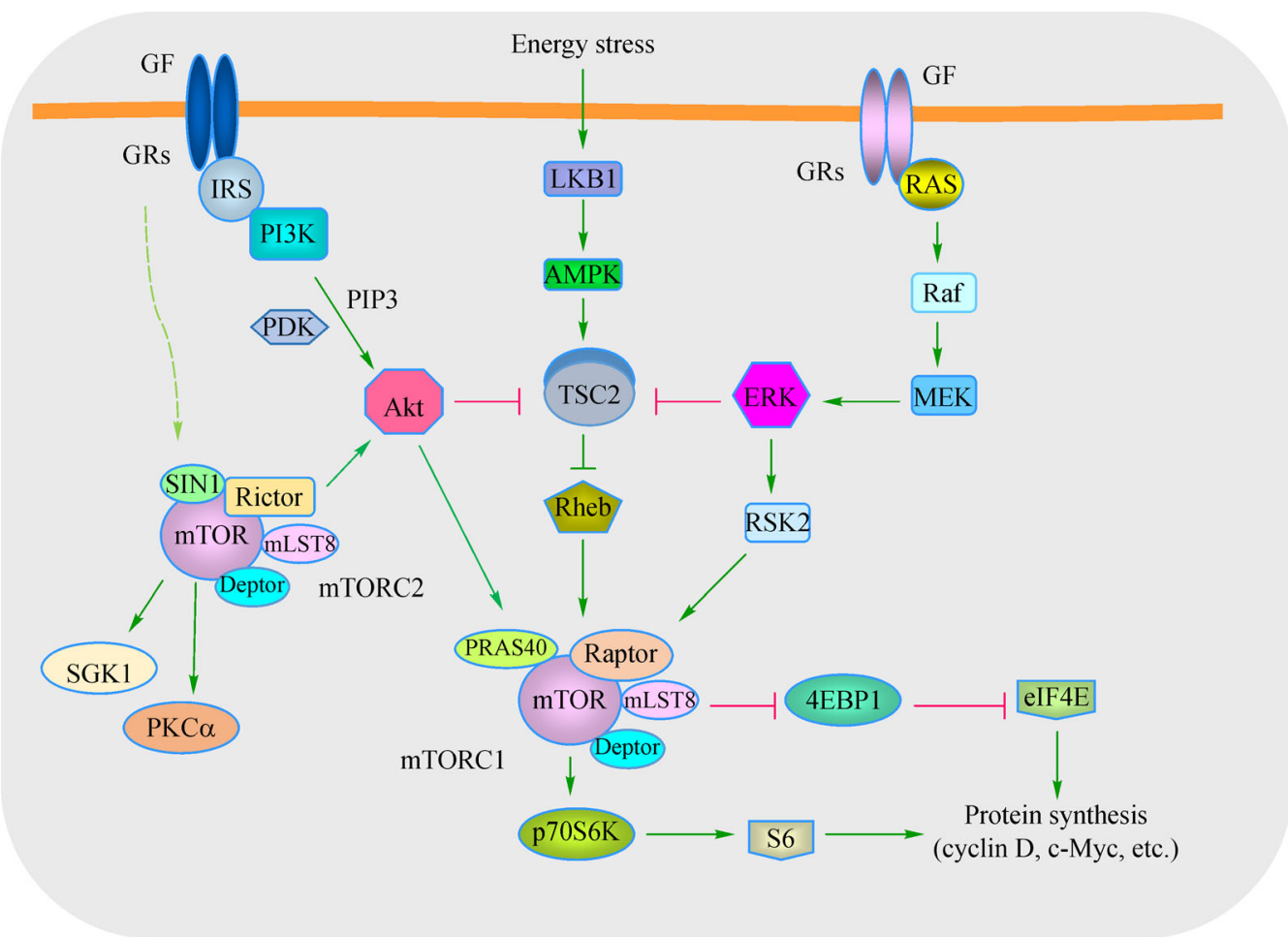

Fig. 1 mTOR complexes and their regulation by various upstream signaling pathways. The PI3K/Akt survival pathway functions upstream to positively regulate the activity of mTORC1 by phosphorylating tuberous sclerosis complex 2 (TSC2); PRAS40, ERK1/2, and p90RSK2 (RSK2) also positively regulate mTORC1 through respective phosphorylation of TSC2 and raptor, thus linking Ras to the positive regulation of mTORC1 signaling. The tumor suppressor, liver kinase B1 (LKB1), inhibits mTORC1 signaling through activation of AMPK and TSC2. Whether the same upstream signals that regulate mTORC1 also regulate mTORC2 is unclear. mTORC2 is known to phosphorylate Akt, SGK1, and PKC $\alpha$, whereas mTORC1 primarily phosphorylates p70S6K and 4EBP1. GF, growth factor; GRs, growth factor receptors; IRS, insulin receptor substrate.

allosteric inhibitors of mTOR and represent first-generation mTOR inhibitors. Some rapalogs (e.g., everolimus/ RAD001 and temsirolimus/CCI-779) are approved by the Food and Drug Administration (FDA) for treatment of certain cancers such as metastatic renal cell carcinoma, pancreatic neuroendocrine tumors, and postmenopausal hormone receptor-positive advanced breast cancer, but the single-agent activity of rapalogs in many other tumor types has been limited [10]. For the past decades, great efforts have been made to develop second-generation ATPcompetitive mTOR kinase inhibitors (TORKinibs), such as INK128, Torin 1, and AZD8055, which suppress mTORC1 and mTORC2 activity, as potential cancer therapeutic agents [11,12], and third-generation bivalent mTOR inhibitors that specifically target mTOR resistance mutations [13] in hopes of developing more efficacious mTOR inhibitors based on the rationale that inhibition of mTORC1 and mTORC2 may achieve better therapeutic efficacy. As a consequence, some TORKinibs have been tested in clinical trials [11,12]. TORKinibs not only represent novel potential anticancer agents but are also valuable research tools for understanding the biology of mTOR signaling. However, TORKinibs have not demonstrated clinical effectiveness against different types of cancer, although the scientific rationale for targeting mTORCs is very strong.

Thus, the intriguing question is, despite such a great target, why are cancer cells insensitive or not responsive to mTOR-targeted cancer therapy, particularly TORKinibbased cancer therapy, in clinics? The current review will focus on discussing possible mechanisms for the resistance of cancer cells to mTOR-targeted cancer therapy.

\section{Induced activation of survival signaling pathways during mTOR-targeted cancer therapy}

mTORC1 functions downstream of the PI3K/Akt signaling pathway. In 2005, we first showed that rapalogs induce Akt phosphorylation (e.g., Ser473) while inhibiting mTORC1 signaling in cancer cells [14]. This observation was subsequently confirmed in other studies in different types of cancer cells [15-17], in xenograft tissues [18] and in human cancer tissues $[15,19,20]$. One potential mechanism underlying rapalog-induced Akt activation is the relief of mTORC1/p70S6K-mediated feedback inhibition of insulin receptor substrate-1 (IRS-1)/PI3K as suggested [15,21]. However, other studies do not support this model $[17,22]$. 
We have suggested that rapalogs induce protein phosphatase 2 (PP2A)-dependent DNA-protein kinase (DNA-PK) activation, resulting in increased Akt phosphorylation [23].

Although mitogen-activated protein kinase (MAPK)/ extracellular signal-regulated kinase (ERK) positively regulates mTORC1 activity [9], studies show that mTORC1 inhibition can also induce feedback activation of MAPK/ERK signaling in cell culture models, mouse tumor models, and, most importantly, cancer tissues from patients [24,25], thereby adding another layer of complexity to the already complicated mTOR signaling network. Similar to activation of PI3K/Akt signaling, mTORC1 inhibition-induced MAPK/ERK activation is thought to be a consequence of p70S6K inhibition and subsequent PI3K activation and in turn activates Ras, causing the activation of MAPK/ERK signaling [24].

Beyond the activation of Akt and ERK survival signaling pathways, rapalogs paradoxically increase eIF4E phosphorylation (Ser209) in various types of cancer cells while inhibiting mTORC1 signaling as we previously reported [14]. Similar to Akt phosphorylation, rapaloginduced eIF4E phosphorylation is rapid and sustained $[14,26]$. We have suggested an underlying mechanism involving PI3K-dependent, MAPK interacting protein kinase (Mnk)-mediated eIF4E phosphorylation but independent of MAPK signaling pathways [14,26].

Given that the blockage of the activation of these pathways enhanced the therapeutic efficacies of rapalogs against the growth of cancer [9], induced activation of PI3K/Akt, MAPK/ERK, and Mnk/eIF4E during rapalogbased cancer therapy will provide survival advantage for cancer cells, eventually blunting the therapeutic efficacies of rapalogs.

\section{Critical role of glycogen synthase kinase-3 (GSK3) in mTOR-targeted cancer therapy}

GSK3 is a ubiquitous serine/threonine kinase that is present in mammals in two isoforms, namely, $\alpha$ and $\beta$ [27]. GSK3 has a key role in regulating multiple cellular functions, including glycogen metabolism, cell survival, and cell death [27]. However, the involvement of GSK3 in the regulation of oncogenesis is complex: it acts paradoxically as a tumor suppressor in some cancer types while potentiating the growth of cancer cells in other types $[28,29]$. Phosphorylation at the S21 $(\alpha)$ and S9 $(\beta)$ of GSK3 by several kinases, such as Akt, p90 ribosomal S6 kinase (p90RSK), PKC, and p70S6K can cause the inactivation of GSK3 [30-32].

GSK3 phosphorylates the turn motif of p70S6K and cooperates with mTORC1 to control the activity of p70S6K and cell proliferation [33]. This finding may provide a rationale for co-targeting mTOR and GSK3 to treat cancer. However, our studies based on this rationale generated opposed outcomes, that is, GSK3 inhibition actually antagonizes the ability of mTOR inhibitors (rapalogs and TORKinibs) to inhibit the growth of nonsmall cell lung cancer (NSCLC) cells in vitro and in vivo, implying that the presence of GSK3 activity is in fact crucial for mTOR inhibitors to exert their anticancer activity [34-36]. Using a panel of different NSCLC cell lines, we reported that the high basal levels of p-GSK3 are significantly correlated with decreased sensitivity of cancer cells to rapalogs and TORKinibs [34,35]. These findings collectively suggest that the presence of activated GSK3 is critical for cancer cells to respond to mTOR-targeted cancer therapy. Considering that other studies show that GSK3 inhibits the mTOR pathway through the phosphorylation of tuberous sclerosis complex 2 (TSC2) in a manner dependent on AMPK-priming phosphorylation [37], where GSK3 is a direct target of S6K1 and is activated upon mTORC1 inhibition [38], however, the real role of GSK3 in mTOR signaling networks is obviously unclear. In our own studies, the inhibition of mTOR with rapalogs and TORKinibs, despite causing strong suppression of p70S6K, does not alter GSK3 phosphorylation $[34,35,39]$.

The intriguing question is why GSK3 is so important for mTOR-targeted cancer therapy. Our initial speculation is that GSK3 inhibition might interfere with the ability of mTOR inhibitors to suppress mTORC1 signaling because it antagonizes the activities of rapalogs and TORKinibs $[34,35]$. Interestingly, GSK3 inhibition does not interfere with the ability of mTOR inhibitors to suppress mTORC1 signaling and cap-dependent binding or eIF4F complex formation. As such, GSK3 inhibition is unlikely to antagonize the therapeutic efficacies of mTOR inhibitors through interfering with their functions in suppressing the mTORC1 signaling. In an effort to find out the real underlying mechanisms, we have revealed that mTORC2 positively regulates the stabilization of several oncogenic proteins, including cyclin D1, Mcl-1, c-Myc, sterol regulatory element binding protein 1 (SREBP1), and Snail, through inhibiting GSK3-dependent and Skp, Cullin, and F-box containing complex (SCF) E3 ubiquitin E3 ligase-mediated proteasomal degradation [35,36,39, 40]. For the first time, these findings have connected mTORC2 to the stabilization of these oncogenic proteins by inhibiting their degradation; this finding represents another layer of regulation of oncogenic proteins in addition to mTORC1-mediated regulation of protein translation (Fig. 2).

One well-known important function of GSK3 is to phosphorylate these oncogenic proteins mentioned above, resulting in their degradation through SCF E3 ubiquitin ligases, including F-box/WD repeat-containing protein 4 (FBXW4), FBXW7, and $\beta$-transducin repeats-containing protein $(\beta-\mathrm{TrCP})$ [41-46]. Hence, GSK3-mediated phosphorylation is a prerequisite for triggering the degradation 

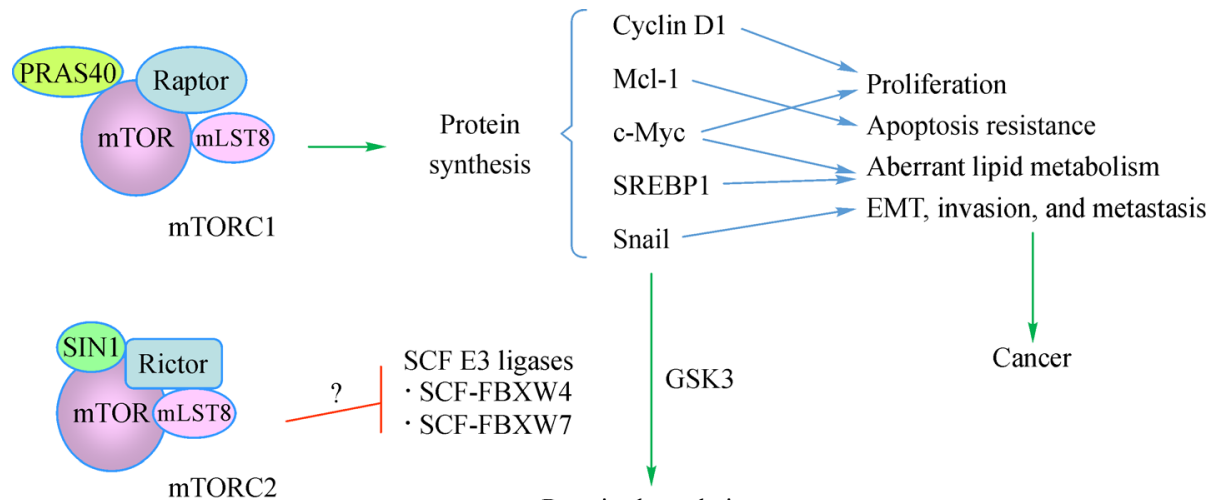

mTORC2

Protein degradation

Fig. 2 Diagram for different layers of regulation of several oncogenic proteins by mTORC1 and mTORC2 at translational and posttranslational levels. Currently, how mTORC2 negatively regulates GSK3-dependent and E3 ubiquitin ligase-mediated protein degradation remains unclear.

of these oncogenic proteins. As such, inhibition of GSK3 will compromise the ability of mTORC2 inhibition to induce the degradation of these oncogenic proteins, which are critical for positive regulation of cell survival, cell cycle progression, and cell invasion/metastasis, as demonstrated in our recent publications $[35,36,39,40]$. As a consequence, the effects of mTOR inhibitors, such as suppression of growth, epithelial-mesenchymal transition (EMT) and migration of cancer cells, will be compromised as a result of GSK3 inactivation. Thus, our findings have demonstrated the critical role of mTORC2 inhibition in the response of cancer cells to mTOR inhibitors.

Rapalogs primarily inhibit mTORC1 with weak or inactive activity against mTORC2. The challenge is that TORKinibs and rapalogs induce GSK3-dependent and SCF E3 ligase-mediated degradation of cyclin D1, Mcl-1, c-Myc, SREBP1, and Snail as consequences of mTORC2 inhibition. Rapalogs inhibit mTORC2 in different systems in vitro and in vivo; however, this effect is largely due to chronic or prolonged rapamycin treatment that can eventually disrupt mTORC2 assembly as reported in literature $[18,47-53]$. Our own data showed that acute treatment with rapamycin (for $1 \mathrm{~h}$ ) disrupted the assembly of not only mTORC1 (mTOR with raptor) but also mTORC2 (mTOR with rictor) in different cancer cell lines [34]. In fact, a previous study did show that rictor was dissociated from mTOR at $0.5-2 \mathrm{~h}$ post rapamycin treatment in few cell lines such as PC-3, BJAB, and Jurkat [47]. Few studies specifically determine the effect of acute rapamycin treatment on mTORC2 assembly in various types of cancer cell lines. We believe that rapalogs, such as rapamycin, have an acute inhibitory effect against the assembly of mTORC2, at least in some cancer cell lines. These findings elucidate why GSK3 inhibition also antagonizes the therapeutic efficacy of rapalogs.

Under the condition of acute treatment with rapamycin,
Akt S473 phosphorylation, a commonly used readout of mTORC2 activity, clearly increased in the tested cell lines [34], consistent with what we initially reported [14]. However, we observed the reduced levels of SGK1 (S422) in every tested cell line under the same conditions [34]. The disruption of the mTORC2 assembly is associated with the suppression of SGK1 S422 phosphorylation. Whether SGK1 S422 phosphorylation serves as a better readout of mTORC2 activity than Akt S473 phosphorylation needs further investigation.

The mutation of PTEN and PIK3CA activates the PI3K/ Akt signaling pathway, leading to the inactivation of GSK3 by phosphorylation, whereas the mutation of K-Ras can also inhibit GSK3 activity via ERK/p90RSK-mediated GSK3 phosphorylation [30]. Given the high frequency of these gene mutations or pathway activation in many types of cancers, GSK3 should be highly phosphorylated (i.e., inactivated) in these cancers. Indeed, GSK3 phosphorylation was detected in $\geqslant 50 \%$ of tissue samples of several human cancers including breast cancer [54], mantle cell lymphoma [55], gastric cancer [56], hepatocellular carcinoma [57], and NSCLC [35]. Hence, many cancer types, particularly those with inactivated GSK3, are insensitive to mTOR-targeted cancer therapy in clinics.

\section{Potential negative impact of E3 ubiquitin ligase mutation on cancer response to mTOR-targeted therapy}

An essential process in proteasomal protein degradation is the ubiquitination of targeted proteins mediated by E3 ubiquitin ligases. In the above-mentioned degradation of cyclin D1, c-Myc, Mcl-1, and SREBP1 induced by mTOR inhibitors, we demonstrated that Mcl-1, c-Myc, and SREBP1 are ubiquitinated by FBXW7 (FBW7) $[39,40]$, whereas cyclin D1 is ubiquitinated by FBX4 (FBXW4) 
[35]. Therefore, mTOR inhibitors will be unable to induce the degradation of these proteins in cancers with inactivation of the E3 ligases due to gene mutations, deletion, or other mechanisms, resulting in limited therapeutic efficacies. $F B X W 7$ has the highest mutation frequency among F-Box and WD repeat domain-containing SCF E3 ubiquitin ligases. The mutation of $F B X W 7$ may reduce the protein's ability to form SCF complexes and/or alter the complex conformation, leading to a non-functional complex [58]. Data from the Catalogue Of Somatic Mutations In Cancer (COSMIC) database revealed the overall FBXW7 mutation rate of 2.54 across all human tumors, among which, endometrium, large intestine, cervix, small intestine, and stomach are the top five tumor types [58]. The Cancer Genome Atlas (TCGA) database search found an overall 5\% FBXW7 mutation rate across all human tumor types. Endometrial carcinoma has the highest $F B X W 7$ mutation rate of up to $20 \%$. Several other types of cancer, including colorectal adenocarcinoma, cervical squamous cell carcinoma, cervical adenocarcinoma, esophagogastric adenocarcinoma, bladder urothelial carcinoma, head and neck squamous cell carcinoma, undifferentiated stomach adenocarcinoma, esophageal squamous cell carcinoma, and melanoma, have high frequencies of $F B X W 7$ mutations, ranging from $15 \%$ to $5 \%$ (Fig. 3A). FBX4 mutations are relatively low in human cancers with an overall rate of around $0.8 \%$ across all human tumors. Endometrial carcinoma, adrenocortical carcinoma, pancreatic carcinoma, and melanoma have the highest frequencies of FBX4 mutations with rates below $2.5 \%$ (Fig. 3B).

In addition to mutations, other mechanisms involving microRNA, long noncoding RNAs, and specific oncogenic signaling pathway activation, can inactivate FBXW7 function in cancer cells $[58,59]$. We assume that these tumors with inactivated SCF E3 ubiquitin ligases, at least some if not all, may not be sensitive to mTOR-targeted cancer therapy. Further study in this regard is warranted.

\section{Upregulation of programmed death-ligand 1 (PD-L1) in cancer cells during mTOR-targeted therapy}

One critical mechanism accounting for immunosuppression and immune escape of cancer cells is the expression of PD-L1 on cancer cells, which can avoid elimination by immune cells, including T cells, natural killer (NK) cells, and macrophages via interacting with program death-1 (PD-1) [60-62]. Immunotherapy targeting the PD-1/PDL1 immune checkpoint has shown promising benefits against several types of cancer and changed the landscape of cancer therapy [63-65].

One early report showed that oncogenic activation of the
Akt/mTOR pathway upregulated PD-L1 expression, thereby promoting immune escape in NSCLC; accordingly, inhibition of this signaling pathway decreased the PD-L1 expression [66]. However, our recent study failed to reproduce this finding; rather we generated opposite results, that is, inhibition of PI3K/Akt or mTORC1/ p70S6K signaling with different corresponding inhibitors increases the PD-L1 levels in NSCLC and other cancer cell lines expressing basal levels of PD-L1. These data were subsequently confirmed using a genetic approach (e.g., shRNA) [67]. In agreement with our findings, another study reported that everolimus increased the cell surface PD-L1 levels in human and murine renal carcinoma cells [68]. In a recent study with renal cell carcinoma cells, inhibition of mTOR with rapamycin and Torin 1 (a TORKinib) increased PD-L1 expression, conferring resistance of renal cell carcinoma to mTOR inhibition [69]. Hence, we believe that inhibition of the PI3K/mTOR pathway actually elevates PD-L1 levels at least in some cancer cells.

Given that PD-L1 expression in cancer cells is a critical mechanism that contributes to immunosuppression and immune escape through its interactions with PD- 1 , it is highly likely that elevated PD-L1 levels on the cancer cell surface may protect cancer cells from being eliminated by immune cells by promoting the immune escape of cancer cells during mTOR-targeted cancer therapy. Therefore, whether PD-L1 induction by mTORC1 inhibition contributes to the modest anticancer activity of rapalogs or limited anticancer activity of TORKinibs is a logical and interesting question to address. This process may represent another important mechanism accounting for the limited success in targeting mTOR for cancer therapy, particularly in vivo or in human. Further study in this direction is warranted.

\section{Other factors that may potentially affect the response of cancer cells to mTOR-targeted cancer therapy}

In addition to the mechanisms discussed above that may specifically account for the limited efficacy of mTORtargeted cancer therapy in clinics, other intrinsic features of cancer cells, such as EMT, cancer stem cell (CSC) phenotype, ATP binding cassette (ABC) transporter expression, and mTOR mutations, may affect the response of cancer cells to mTOR inhibitors (see review by Hua et al. [70]).

Some of these factors, such as EMT, CSC, and ABC transporters, may not be mechanisms specific to mTOR inhibitors; they can also be cell type- and inhibitordependent. For example, while breast cancer cell lines with high EMT feature are relatively insensitive to rapamycin 


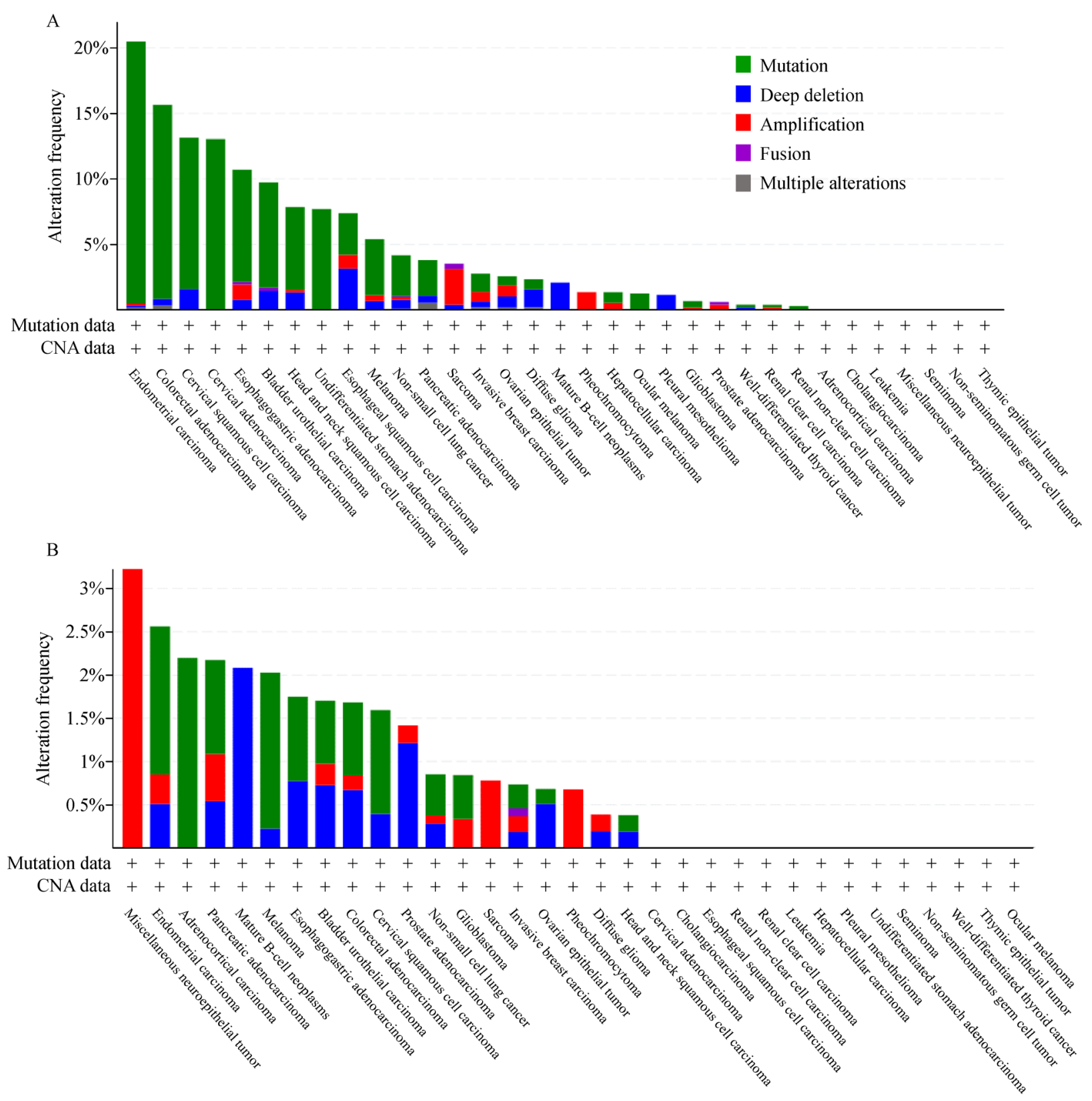

Fig. 3 TCGA analyses for $F B X W 7$ (A) and FBX4 (B) mutations in human cancers. These data were generated from the website of https://www.cbioportal.org/.

and modulation of EMT accordingly alters cell sensitivity to rapamycin [71], TORKinibs and rapalogs effectively inhibit EMT and migration of NSCLC cells through facilitation of Snail degradation and in vivo metastasis, as evaluated in a genetically engineered murine breast cancer model [36]. Patient-derived glioblastoma stem-like cell cultures (GSCs) harboring wild-type p53 are insensitive to the mTORKinib, AZD8055, whereas GSCs with mutant p53 are sensitive to the inhibitor [72]. In colon cancer cells, PDK1-Polo-like kinase 1 (PLK1)-MYC signaling functions as a new oncogenic pathway driving oncogenic transformation and CSC self-renewal and is associated with resistance to mTOR inhibitors [73]. However, total breast cancer cells and sorted stem cells are sensitive to everolimus in vitro and in vivo [74]. Given that rapamycin, AZD8055, and WYE-354 are substrates of ATP binding cassette sub-family B member 1 (ABCB1)/P-glycoprotein or multidrug resistance protein 1 (MDR1) [75,76], the efficacies of these mTOR inhibitors may be compromised in cancer cells with highly expressed ABCB1. Interestingly, Palomid 529, a novel TORKinib, lacks affinity for ABCB1 with good brain penetration [77]. 


\section{Opportunities for enhancing mTOR- targeted cancer therapy}

Strategies toward induced induction of survival signaling pathways, including PI3K/Akt, MEK/ERK, and Mnk/ eIF4E, for enhancing mTOR-targeted cancer therapy have been discussed in detail in our previous review [9].

As discussed above, GSK3 activity is required for mTOR inhibitors, including rapalogs and TORKinibs, to induce the degradation of certain oncogenic proteins, such as cyclin D1, Mcl-1, and SREBP1, and to inhibit tumor cell growth $[34,35,39,40]$. Moreover, basal p-GSK3 levels are inversely correlated to cell sensitivity to mTOR inhibitors in human NSCLC cells $[34,35]$. Hence, the activation of GSK3 is speculated to enhance the anticancer efficacy of mTOR inhibitors, particularly in tumors with low GSK3 activity (or highly phosphorylated GSK3). However, directly targeting GSK3 activation in cancer therapy is difficult considering the complex roles of GSK3 in regulation of cancer development [28,29]. Moreover, GSK3 activation may cause other issues related to neurodegenerative diseases $[78,79]$.

PI3K/Akt and MEK/ERK/p90RSK signaling pathways positively regulate GSK3 phosphorylation [30-32]. Targeting these signaling pathways may indirectly activate GSK3, thereby achieving enhanced therapeutic effects when combined with mTOR-targeted therapy. Some published studies reported the enhanced antitumor effects of mTOR inhibition in vitro and in vivo when combined with PI3K/Akt inhibition [25,80-83] or with MEK/ERK inhibition [84-87] despite having different rationales and mechanisms. Whether GSK3 activation contributes to these enhanced antitumor effects needs further investigation.

Although rapalogs have long been regarded as immunosuppressants and are used in organ transplantation, many recent studies suggest that the effects of rapamycin on immune function, particularly $\mathrm{T}$ cell activation, are highly dose dependent [88-91]. Low doses of rapamycin stimulate memory $\mathrm{CD} 8^{+} \mathrm{T}$ cell generation and enhance the memory $\mathrm{T}$ cell response to viral infection or cancer in mice [92]. Similarly, everolimus at low doses improves immune function in elderly volunteers, as assessed by their response to influenza vaccination [93]. A human study in patients with renal cancer showed that the therapeutic efficacy of rapalogs is associated with modulation of antitumor T cell immunity. Patients treated with rapalogs showed better clinical responses if they presented a shift toward decreased Treg levels and high expansion of antitumor Th1 or activated $\mathrm{CD} 8^{+} \mathrm{T}$ cells [94]. Several works have shown that rapalogs enhance response to various modalities of immunotherapy, including adoptive cell therapy and cancer vaccines [95-98].

In theory, the elevation of PD-L1 in cancer cells might increase the availability of epitopes for anti-PD-L1 antibody to bind, which could enhance the efficacy of anti-PDL1 therapy. Therefore, the positive impact of mTOR inhibition on generation and activation of memory $\mathrm{CD} 8^{+} \mathrm{T}$ cells and on elevation of PD-L1 in cancer cells may constitute a strong scientific rationale for combining mTOR inhibition with PD-1 or PD-L1 blockade immunotherapy as an effective strategy to enhance therapeutic efficacy. The combination of everolimus or rapamycin with PD-L1 blockade significantly enhanced antitumor activity compared with each single agent treatment against renal and oral cavity cancers $[68,99]$. The combination of rapamycin with anti-PD-1 antibody also enhanced the reduction of lung tumor burden in a mutant $K R A S$-driven mouse lung cancer model [66]. Another recent study showed that simultaneous inhibition of mTOR with temsirolimus and blockade of PD-L1 enhanced $\mathrm{CD}^{+}$ cytolytic function and tumor suppression in a xenografted mouse model of renal cell carcinoma based on the rationale of mTOR inhibition-induced upregulation of PD-L1 expression [69].

\section{Summary and conclusions}

On top of the early findings on induced activation of PI3K/ Akt, MEK/ERK, and Mnk/eIF4E survival signaling pathways that blunt the efficacy of mTOR-targeted cancer therapy, recent studies have further shown the essential role of GSK3 in mediating cancer cell response to mTOR inhibitors and the potential negative effect of induced upregulation of PD-L1 in cancer cells on mTOR-targeted cancer therapy. These findings not only suggest the complexity of mTOR networks but also have complicated the story of mTOR-targeted therapy. Full elucidation of the biology of mTOR networks and potential resistance mechanisms in mTOR-targeted cancer therapy will eventually help us to better utilize mTOR inhibitors in a rational manner for effective treatment of cancer. The hope is there, but there is a long way ahead of us.

\section{Acknowledgements}

I am grateful to Dr. Karin A. Albuerne in my laboratory for editing the manuscript. Shi-Yong Sun is a Georgia Research Alliance Distinguished Cancer Scientist.

\section{Compliance with ethics guidelines}

Shi-Yong Sun declares no conflict of interest. This manuscript is a review article and does not involve a research protocol requiring approval by the relevant institutional review board or ethics committee.

Open Access This article is licensed under a Creative Commons 
Attribution 4.0 International License, which permits use, sharing, adaptation, distribution and reproduction in any medium or format, as long as you give appropriate credit to the original author(s) and the source, provide a link to the Creative Commons licence, and indicate if changes were made.

The images or other third party material in this article are included in the article's Creative Commons licence, unless indicated otherwise in a credit line to the material. If material is not included in the article's Creative Commons licence and your intended use is not permitted by statutory regulation or exceeds the permitted use, you will need to obtain permission directly from the copyright holder.

To view a copy of this licence, visit https://creativecommons.org/ licenses/by/4.0/.

\section{References}

1. Guertin DA, Sabatini DM. Defining the role of mTOR in cancer. Cancer Cell 2007; 12(1): 9-22

2. Oh WJ, Jacinto E. mTOR complex 2 signaling and functions. Cell Cycle 2011; 10(14): 2305-2316

3. Laplante M, Sabatini DM. mTOR signaling at a glance. J Cell Sci 2009; 122(Pt 20): 3589-3594

4. Cai W, Ye Q, She QB. Loss of 4E-BP1 function induces EMT and promotes cancer cell migration and invasion via cap-dependent translational activation of snail. Oncotarget 2014; 5(15): 6015-6027

5. Guertin DA, Stevens DM, Saitoh M, Kinkel S, Crosby K, Sheen JH, Mullholland DJ, Magnuson MA, Wu H, Sabatini DM. mTOR complex 2 is required for the development of prostate cancer induced by Pten loss in mice. Cancer Cell 2009; 15(2): 148-159

6. Lee K, Nam KT, Cho SH, Gudapati P, Hwang Y, Park DS, Potter R, Chen J, Volanakis E, Boothby M. Vital roles of mTOR complex 2 in Notch-driven thymocyte differentiation and leukemia. J Exp Med 2012; 209(4): 713-728

7. Roulin D, Cerantola Y, Dormond-Meuwly A, Demartines N, Dormond O. Targeting mTORC2 inhibits colon cancer cell proliferation in vitro and tumor formation in vivo. Mol Cancer 2010; 9(1): 57

8. Sun SY. Impact of genetic alterations on mTOR-targeted cancer therapy. Chin J Cancer 2013; 32(5): 270-274

9. Wang X, Sun SY. Enhancing mTOR-targeted cancer therapy. Expert Opin Ther Targets 2009; 13(10): 1193-1203

10. Abraham RT, Gibbons JJ. The mammalian target of rapamycin signaling pathway: twists and turns in the road to cancer therapy. Clin Cancer Res 2007; 13(11): 3109-3114

11. Sun SY. mTOR kinase inhibitors as potential cancer therapeutic drugs. Cancer Lett 2013; 340(1): 1-8

12. Zhang YJ, Duan Y, Zheng XF. Targeting the mTOR kinase domain: the second generation of mTOR inhibitors. Drug Discov Today 2011; 16(7-8): 325-331

13. Rodrik-Outmezguine VS, Okaniwa M, Yao Z, Novotny CJ, McWhirter C, Banaji A, Won H, Wong W, Berger M, de Stanchina E, Barratt DG, Cosulich S, Klinowska T, Rosen N, Shokat KM. Overcoming mTOR resistance mutations with a new-generation mTOR inhibitor. Nature 2016; 534(7606): 272-276
14. Sun SY, Rosenberg LM, Wang X, Zhou Z, Yue P, Fu H, Khuri FR. Activation of Akt and eIF4E survival pathways by rapamycinmediated mammalian target of rapamycin inhibition. Cancer Res 2005; 65(16): 7052-7058

15. O'Reilly KE, Rojo F, She QB, Solit D, Mills GB, Smith D, Lane H, Hofmann F, Hicklin DJ, Ludwig DL, Baselga J, Rosen N. mTOR inhibition induces upstream receptor tyrosine kinase signaling and activates Akt. Cancer Res 2006; 66(3): 1500-1508

16. Shi Y, Yan H, Frost P, Gera J, Lichtenstein A. Mammalian target of rapamycin inhibitors activate the AKT kinase in multiple myeloma cells by up-regulating the insulin-like growth factor receptor/insulin receptor substrate-1/phosphatidylinositol 3-kinase cascade. Mol Cancer Ther 2005; 4(10): 1533-1540

17. Wan X, Harkavy B, Shen N, Grohar P, Helman LJ. Rapamycin induces feedback activation of Akt signaling through an IGF-1Rdependent mechanism. Oncogene 2007; 26(13): 1932-1940

18. Wang X, Yue P, Kim YA, Fu H, Khuri FR, Sun SY. Enhancing mammalian target of rapamycin (mTOR)-targeted cancer therapy by preventing $\mathrm{mTOR} /$ raptor inhibition-initiated, $\mathrm{mTOR} /$ rictor-independent Akt activation. Cancer Res 2008; 68(18): 7409-7418

19. Duran I, Kortmansky J, Singh D, Hirte H, Kocha W, Goss G, Le L, Oza A, Nicklee T, Ho J, Birle D, Pond GR, Arboine D, Dancey J, Aviel-Ronen S, Tsao MS, Hedley D, Siu LL. A phase II clinical and pharmacodynamic study of temsirolimus in advanced neuroendocrine carcinomas. Br J Cancer 2006; 95(9): 1148-1154

20. Tabernero J, Rojo F, Calvo E, Burris H, Judson I, Hazell K, Martinelli E, Ramon y Cajal S, Jones S, Vidal L, Shand N, Macarulla T, Ramos FJ, Dimitrijevic S, Zoellner U, Tang P, Stumm M, Lane HA, Lebwohl D, Baselga J. Dose- and schedule-dependent inhibition of the mammalian target of rapamycin pathway with everolimus: a phase I tumor pharmacodynamic study in patients with advanced solid tumors. J Clin Oncol 2008; 26(10): 1603-1610

21. Easton JB, Kurmasheva RT, Houghton PJ. IRS-1: auditing the effectiveness of mTOR inhibitors. Cancer Cell 2006; 9(3): 153-155

22. Wang X, Yue P, Tao H, Sun SY. Inhibition of p70S6K does not mimic the enhancement of Akt phosphorylation by rapamycin. Heliyon 2017; 3(8): e00378

23. Li Y, Wang X, Yue P, Tao H, Ramalingam SS, Owonikoko TK, Deng X, Wang Y, Fu H, Khuri FR, Sun SY. Protein phosphatase 2A and DNA-dependent protein kinase are involved in mediating rapamycin-induced Akt phosphorylation. J Biol Chem 2013; 288 (19): 13215-13224

24. Carracedo A, Ma L, Teruya-Feldstein J, Rojo F, Salmena L, Alimonti A, Egia A, Sasaki AT, Thomas G, Kozma SC, Papa A, Nardella C, Cantley LC, Baselga J, Pandolfi PP. Inhibition of mTORC1 leads to MAPK pathway activation through a PI3Kdependent feedback loop in human cancer. J Clin Invest 2008; 118 (9): 3065-3074

25. Wang X, Hawk N, Yue P, Kauh J, Ramalingam SS, Fu H, Khuri FR, Sun SY. Overcoming mTOR inhibition-induced paradoxical activation of survival signaling pathways enhances mTOR inhibitors' anticancer efficacy. Cancer Biol Ther 2008; 7(12): 1952-1958

26. Wang X, Yue P, Chan CB, Ye K, Ueda T, Watanabe-Fukunaga R, Fukunaga R, Fu H, Khuri FR, Sun SY. Inhibition of mammalian target of rapamycin induces phosphatidylinositol 3 kinase-dependent and Mnk-mediated eIF4E phosphorylation. Mol Cell Biol 2007; 27(21): 7405-7413 
27. Frame S, Cohen P. GSK 3 takes centre stage more than 20 years after its discovery. Biochem J 2001; 359(Pt 1): 1-16

28. Mills CN, Nowsheen S, Bonner JA, Yang ES. Emerging roles of glycogen synthase kinase 3 in the treatment of brain tumors. Front Mol Neurosci 2011; 4: 47

29. Mishra R. Glycogen synthase kinase $3 \beta$ : can it be a target for oral cancer. Mol Cancer 2010; 9(1): 144

30. Cohen P, Frame S. The renaissance of GSK3. Nat Rev Mol Cell Biol 2001; 2(10): 769-776

31. McCubrey JA, Davis NM, Abrams SL, Montalto G, Cervello M, Basecke J, Libra M, Nicoletti F, Cocco L, Martelli AM, Steelman LS. Diverse roles of GSK-3: tumor promoter-tumor suppressor, target in cancer therapy. Adv Biol Regul 2014; 54: 176-196

32. Medina M, Wandosell F. Deconstructing GSK-3: the fine regulation of its activity. Int J Alzheimers Dis 2011; 2011: 479249

33. Shin S, Wolgamott L, Yu Y, Blenis J, Yoon SO. Glycogen synthase kinase (GSK)-3 promotes p70 ribosomal protein S6 kinase (p70S6K) activity and cell proliferation. Proc Natl Acad Sci USA 2011; 108(47): E1204-E1213

34. Koo J, Wang X, Owonikoko TK, Ramalingam SS, Khuri FR, Sun SY. GSK3 is required for rapalogs to induce degradation of some oncogenic proteins and to suppress cancer cell growth. Oncotarget 2015; 6(11): 8974-8987

35. Koo J, Yue P, Gal AA, Khuri FR, Sun SY. Maintaining glycogen synthase kinase-3 activity is critical for mTOR kinase inhibitors to inhibit cancer cell growth. Cancer Res 2014; 74(9): 2555-2568

36. Zhang S, Qian G, Zhang QQ, Yao Y, Wang D, Chen ZG, Wang LJ, Chen M, Sun SY. mTORC2 suppresses GSK3-dependent Snail degradation to positively regulate cancer cell invasion and metastasis. Cancer Res 2019; 79(14): 3725-3736

37. Inoki K, Ouyang H, Zhu T, Lindvall C, Wang Y, Zhang X, Yang Q, Bennett C, Harada Y, Stankunas K, Wang CY, He X, MacDougald OA, You M, Williams BO, Guan KL. TSC2 integrates Wnt and energy signals via a coordinated phosphorylation by AMPK and GSK3 to regulate cell growth. Cell 2006; 126(5): 955-968

38. Zhang HH, Lipovsky AI, Dibble CC, Sahin M, Manning BD. S6K1 regulates GSK3 under conditions of mTOR-dependent feedback inhibition of Akt. Mol Cell 2006; 24(2): 185-197

39. Koo J, Yue P, Deng X, Khuri FR, Sun SY. mTOR complex 2 stabilizes Mcl-1 protein by suppressing its GSK3-dependent and SCF-FBXW7-mediated degradation. Mol Cell Biol 2015; 35: 2344 2355

40. Li S, Oh YT, Yue P, Khuri FR, Sun SY. Inhibition of mTOR complex 2 induces GSK3/FBXW7-dependent degradation of sterol regulatory element-binding protein 1 (SREBP1) and suppresses lipogenesis in cancer cells. Oncogene 2016; 35(5): 642-650

41. Welcker M, Clurman BE. FBW7 ubiquitin ligase: a tumour suppressor at the crossroads of cell division, growth and differentiation. Nat Rev Cancer 2008; 8(2): 83-93

42. Inuzuka H, Shaik S, Onoyama I, Gao D, Tseng A, Maser RS, Zhai B, Wan L, Gutierrez A, Lau AW, Xiao Y, Christie AL, Aster J, Settleman J, Gygi SP, Kung AL, Look T, Nakayama KI, DePinho RA, Wei W. SCF(FBW7) regulates cellular apoptosis by targeting MCL1 for ubiquitylation and destruction. Nature 2011; 471(7336): 104-109

43. Takahashi-Yanaga F, Sasaguri T. GSK-3 $\beta$ regulates cyclin D1 expression: a new target for chemotherapy. Cell Signal 2008; 20(4):
$581-589$

44. Cuadrado A. Structural and functional characterization of Nrf2 degradation by glycogen synthase kinase $3 / \beta-\operatorname{TrCP}$. Free Radic Biol Med 2015; 88(Pt B): 147-157

45. Xu C, Kim NG, Gumbiner BM. Regulation of protein stability by GSK3 mediated phosphorylation. Cell Cycle 2009; 8(24): 40324039

46. Zhou BP, Deng J, Xia W, Xu J, Li YM, Gunduz M, Hung MC. Dual regulation of Snail by GSK-3 $\beta$-mediated phosphorylation in control of epithelial-mesenchymal transition. Nat Cell Biol 2004; 6(10): 931-940

47. Sarbassov DD, Ali SM, Sengupta S, Sheen JH, Hsu PP, Bagley AF, Markhard AL, Sabatini DM. Prolonged rapamycin treatment inhibits mTORC2 assembly and Akt/PKB. Mol Cell 2006; 22(2): 159-168

48. Barilli A, Visigalli R, Sala R, Gazzola GC, Parolari A, Tremoli E, Bonomini S, Simon A, Closs EI, Dall'Asta V, Bussolati O. In human endothelial cells rapamycin causes mTORC2 inhibition and impairs cell viability and function. Cardiovasc Res 2008; 78(3): $563-571$

49. Rosner M, Hengstschläger M. Cytoplasmic and nuclear distribution of the protein complexes mTORC1 and mTORC2: rapamycin triggers dephosphorylation and delocalization of the mTORC2 components rictor and sin1. Hum Mol Genet 2008; 17(19): 29342948

50. Barquilla A, Crespo JL, Navarro M. Rapamycin inhibits trypanosome cell growth by preventing TOR complex 2 formation. Proc Natl Acad Sci USA 2008; 105(38): 14579-14584

51. Barlow AD, Xie J, Moore CE, Campbell SC, Shaw JA, Nicholson ML, Herbert TP. Rapamycin toxicity in MIN6 cells and rat and human islets is mediated by the inhibition of mTOR complex 2 (mTORC2). Diabetologia 2012; 55(5): 1355-1365

52. Lamming DW, Ye L, Katajisto P, Goncalves MD, Saitoh M, Stevens DM, Davis JG, Salmon AB, Richardson A, Ahima RS, Guertin DA, Sabatini DM, Baur JA. Rapamycin-induced insulin resistance is mediated by mTORC2 loss and uncoupled from longevity. Science 2012; 335(6076): 1638-1643

53. Hong SM, Park CW, Cha HJ, Kwon JH, Yun YS, Lee NG, Kim DG, Nam HG, Choi KY. Rapamycin inhibits both motility through down-regulation of p-STAT3 (S727) by disrupting the mTORC2 assembly and peritoneal dissemination in sarcomatoid cholangiocarcinoma. Clin Exp Metastasis 2013; 30(2): 177-187

54. Ding Q, He X, Xia W, Hsu JM, Chen CT, Li LY, Lee DF, Yang JY, Xie X, Liu JC, Hung MC. Myeloid cell leukemia-1 inversely correlates with glycogen synthase kinase- $3 \beta$ activity and associates with poor prognosis in human breast cancer. Cancer Res 2007; 67 (10): 4564-4571

55. Chung R, Peters AC, Armanious H, Anand M, Gelebart P, Lai R. Biological and clinical significance of GSK-3 $\beta$ in mantle cell lymphoma - an immunohistochemical study. Int J Clin Exp Pathol 2010; 3(3): 244-253 PMID:20224723

56. Cho YJ, Kim JH, Yoon J, Cho SJ, Ko YS, Park JW, Lee HS, Lee HE, Kim WH, Lee BL. Constitutive activation of glycogen synthase kinase-3 $\beta$ correlates with better prognosis and cyclin-dependent kinase inhibitors in human gastric cancer. BMC Gastroenterol 2010; 10(1): 91

57. Qiao G, Le Y, Li J, Wang L, Shen F. Glycogen synthase kinase- $3 \beta$ is 
associated with the prognosis of hepatocellular carcinoma and may mediate the influence of type 2 diabetes mellitus on hepatocellular carcinoma. PLoS One 2014; 9(8): e105624

58. Yeh CH, Bellon M, Nicot C. FBXW7: a critical tumor suppressor of human cancers. Mol Cancer 2018; 17(1): 115

59. Davis RJ, Welcker M, Clurman BE. Tumor suppression by the Fbw7 ubiquitin ligase: mechanisms and opportunities. Cancer Cell 2014; 26(4): 455-464

60. Guan J, Lim KS, Mekhail T, Chang CC. Programmed death ligand-1 (PD-L1) expression in the programmed death receptor-1 (PD-1)/PDL1 blockade: a key player against various cancers. Arch Pathol Lab Med 2017; 141(6): 851-861

61. Benson DM Jr, Bakan CE, Mishra A, Hofmeister CC, Efebera Y, Becknell B, Baiocchi RA, Zhang J, Yu J, Smith MK, Greenfield CN, Porcu P, Devine SM, Rotem-Yehudar R, Lozanski G, Byrd JC, Caligiuri MA. The PD-1/PD-L1 axis modulates the natural killer cell versus multiple myeloma effect: a therapeutic target for CT-011, a novel monoclonal anti-PD-1 antibody. Blood 2010; 116(13): 2286-2294

62. Gordon SR, Maute RL, Dulken BW, Hutter G, George BM, McCracken MN, Gupta R, Tsai JM, Sinha R, Corey D, Ring AM, Connolly AJ, Weissman IL. PD-1 expression by tumour-associated macrophages inhibits phagocytosis and tumour immunity. Nature 2017; 545(7655): 495-499

63. Iwai Y, Hamanishi J, Chamoto K, Honjo T. Cancer immunotherapies targeting the PD-1 signaling pathway. J Biomed Sci 2017; 24 (1): 26

64. Somasundaram A, Burns TF. The next generation of immunotherapy: keeping lung cancer in check. J Hematol Oncol 2017; 10(1): 87

65. Stambrook PJ, Maher J, Farzaneh F. Cancer immunotherapy: whence and whither. Mol Cancer Res 2017; 15(6): 635-650

66. Lastwika KJ, Wilson W 3rd, Li QK, Norris J, Xu H, Ghazarian SR, Kitagawa H, Kawabata S, Taube JM, Yao S, Liu LN, Gills JJ, Dennis PA. Control of PD-L1 expression by oncogenic activation of the AKT-mTOR pathway in non-small cell lung cancer. Cancer Res 2016; 76(2): 227-238

67. Deng L, Qian G, Zhang S, Zheng H, Fan S, Lesinski GB, Owonikoko TK, Ramalingam SS, Sun SY. Inhibition of mTOR complex 1/p70 S6 kinase signaling elevates PD-L1 levels in human cancer cells through enhancing protein stabilization accompanied with enhanced $\beta$-TrCP degradation. Oncogene 2019; 38(35): 62706282

68. Hirayama Y, Gi M, Yamano S, Tachibana H, Okuno T, Tamada S, Nakatani T, Wanibuchi H. Anti-PD-L1 treatment enhances antitumor effect of everolimus in a mouse model of renal cell carcinoma. Cancer Sci 2016; 107(12): 1736-1744

69. Zhang C, Duan Y, Xia M, Dong Y, Chen Y, Zheng L, Chai S, Zhang Q, Wei Z, Liu N, Wang J, Sun C, Tang Z, Cheng X, Wu J, Wang G, Zheng F, Laurence A, Li B, Yang XP. TFEB mediates immune evasion and resistance to $\mathrm{mTOR}$ inhibition of renal cell carcinoma via induction of PD-L1. Clin Cancer Res 2019; 25(22): 6827-6838

70. Hua H, Kong Q, Zhang H, Wang J, Luo T, Jiang Y. Targeting mTOR for cancer therapy. J Hematol Oncol 2019; 12(1): 71

71. Holder AM, Akcakanat A, Adkins F, Evans K, Chen H, Wei C, Milton DR, Li Y, Do KA, Janku F, Meric-Bernstam F. Epithelial to mesenchymal transition is associated with rapamycin resistance. Oncotarget 2015; 6(23): 19500-19513
72. Venkatesan S, Hoogstraat M, Caljouw E, Pierson T, Spoor JK, Zeneyedpour L, Dubbink HJ, Dekker LJ, van der Kaaij M, Kloezeman J, Berghauser Pont LM, Besselink NJ, Luider TM, Joore J, Martens JW, Lamfers ML, Sleijfer S, Leenstra S. TP53 mutated glioblastoma stem-like cell cultures are sensitive to dual mTORC1/2 inhibition while resistance in TP53 wild type cultures can be overcome by combined inhibition of mTORC1/2 and Bcl-2. Oncotarget 2016; 7(36): 58435-58444

73. Tan J, Li Z, Lee PL, Guan P, Aau MY, Lee ST, Feng M, Lim CZ, Lee EY, Wee ZN, Lim YC, Karuturi RK, Yu Q. PDK1 signaling toward PLK1-MYC activation confers oncogenic transformation, tumor-initiating cell activation, and resistance to mTOR-targeted therapy. Cancer Discov 2013; 3(10): 1156-1171

74. Liu Y, Zhang X, Liu P, Zhang J. Drug sensitivity research of mTOR inhibitor on breast cancer stem cells. Natl Med J China (Zhonghua Yi Xue Za Zhi) 2015; 95(24): 1910-1914 (in Chinese)

75. Lin F, de Gooijer MC, Hanekamp D, Chandrasekaran G, Buil LC, Thota N, Sparidans RW, Beijnen JH, Würdinger T, van Tellingen O. PI3K-mTOR pathway inhibition exhibits efficacy against highgrade glioma in clinically relevant mouse models. Clin Cancer Res 2017; 23(5): 1286-1298

76. Wang J, Yang DH, Yang Y, Wang JQ, Cai CY, Lei ZN, Teng QX, Wu ZX, Zhao L, Chen ZS. Overexpression of ABCB1 transporter confers resistance to mTOR inhibitor WYE-354 in cancer cells. Int J Mol Sci 2020; 21(4): E1387

77. Lin F, Buil L, Sherris D, Beijnen JH, van Tellingen O. Dual mTORC1 and mTORC2 inhibitor Palomid 529 penetrates the blood-brain barrier without restriction by $\mathrm{ABCB} 1$ and $\mathrm{ABCG} 2$. Int $\mathrm{J}$ Cancer 2013; 133(5): 1222-1233

78. Lauretti E, Dincer O, Praticò D. Glycogen synthase kinase-3 signaling in Alzheimer's disease. Biochim Biophys Acta Mol Cell Res 2020; 1867(5): 118664

79. Duda P, Wiśniewski J, Wójtowicz T, Wójcicka O, Jaśkiewicz M, Drulis-Fajdasz D, Rakus D, McCubrey JA, Gizak A. Targeting GSK3 signaling as a potential therapy of neurodegenerative diseases and aging. Expert Opin Ther Targets 2018; 22(10): 833-848

80. Lynch JT, Polanska UM, Hancox U, Delpuech O, Maynard J, Trigwell C, Eberlein C, Lenaghan C, Polanski R, Avivar-Valderas A, Cumberbatch M, Klinowska T, Critchlow SE, Cruzalegui F, Barry ST. Combined inhibition of PI3K $\beta$ and mTOR inhibits growth of PTEN-null tumors. Mol Cancer Ther 2018; 17(11): 2309-2319

81. Kim H, Lee SJ, Lee IK, Min SC, Sung HH, Jeong BC, Lee J, Park $\mathrm{SH}$. Synergistic effects of combination therapy with AKT and mTOR inhibitors on bladder cancer cells. Int J Mol Sci 2020; 21(8): E2825

82. Mazzoletti M, Bortolin F, Brunelli L, Pastorelli R, Di Giandomenico S, Erba E, Ubezio P, Broggini M. Combination of PI3K/mTOR inhibitors: antitumor activity and molecular correlates. Cancer Res 2011; 71(13): 4573-4584

83. Mise J, Dembitz V, Banfic H, Visnjic D. Combined inhibition of PI3K and mTOR exerts synergistic antiproliferative effect, but diminishes differentiative properties of rapamycin in acute myeloid leukemia cells. Pathol Oncol Res 2011; 17(3): 645-656

84. Arnold A, Yuan M, Price A, Harris L, Eberhart CG, Raabe EH. Synergistic activity of mTORC1/2 kinase and MEK inhibitors suppresses pediatric low-grade glioma tumorigenicity and vascularity. Neuro-oncol 2020; 22(4): 563-574 
85. Liu X, Hu J, Song X, Utpatel K, Zhang Y, Wang P, Lu X, Zhang J, $\mathrm{Xu} \mathrm{M}, \mathrm{Su} \mathrm{T}$, Che L, Wang J, Evert M, Calvisi DF, Chen X. Combined treatment with MEK and mTOR inhibitors is effective in in vitro and in vivo models of hepatocellular carcinoma. Cancers (Basel) 2019; 11(7): E930

86. Chadwick ML, Lane A, Thomas D, Smith AR, White AR, Davidson D, Feng Y, Boscolo E, Zheng Y, Adams DM, Gupta A, Veillette A, Chow LML. Combined mTOR and MEK inhibition is an effective therapy in a novel mouse model for angiosarcoma. Oncotarget 2018; 9(37): 24750-24765

87. Andersen NJ, Boguslawski EB, Kuk CY, Chambers CM, Duesbery NS. Combined inhibition of MEK and mTOR has a synergic effect on angiosarcoma tumorgrafts. Int J Oncol 2015; 47(1): 71-80

88. Araki K, Youngblood B, Ahmed R. The role of mTOR in memory CD8 T-cell differentiation. Immunol Rev 2010; 235(1): 234-243

89. Chi H. Regulation and function of mTOR signalling in $\mathrm{T}$ cell fate decisions. Nat Rev Immunol 2012; 12(5): 325-338

90. Chapman NM, Chi H. mTOR signaling, Tregs and immune modulation. Immunotherapy 2014; 6(12): 1295-1311

91. Fantus D, Thomson AW. Evolving perspectives of mTOR complexes in immunity and transplantation. Am J Transplant 2015; 15(4): 891-902

92. Araki K, Turner AP, Shaffer VO, Gangappa S, Keller SA, Bachmann MF, Larsen CP, Ahmed R. mTOR regulates memory CD8 T-cell differentiation. Nature 2009; 460(7251): 108-112

93. Mannick JB, Del Giudice G, Lattanzi M, Valiante NM, Praestgaard J, Huang B, Lonetto MA, Maecker HT, Kovarik J, Carson S, Glass DJ, Klickstein LB. mTOR inhibition improves immune function in the elderly. Sci Transl Med 2014; 6(268): 268 ra179

94. Beziaud L, Mansi L, Ravel P, Marie-Joseph EL, Laheurte C, Rangan L, Bonnefoy F, Pallandre JR, Boullerot L, Gamonet C, Vrecko S, Queiroz L, Maurina T, Mouillet G, Hon TN, Curtit E, Royer B, Gaugler B, Bayry J, Tartour E, Thiery-Vuillemin A, Pivot X, Borg C, Godet Y, Adotévi O. Rapalogs efficacy relies on the modulation of antitumor T-cell immunity. Cancer Res 2016; 76(14): 4100-4112

95. Amiel E, Everts B, Freitas TC, King IL, Curtis JD, Pearce EL, Pearce EJ. Inhibition of mechanistic target of rapamycin promotes dendritic cell activation and enhances therapeutic autologous vaccination in mice. J Immunol 2012; 189(5): 2151-2158

96. Thomas DL, Doty R, Tosic V, Liu J, Kranz DM, McFadden G, Macneill AL, Roy EJ. Myxoma virus combined with rapamycin treatment enhances adoptive $\mathrm{T}$ cell therapy for murine melanoma brain tumors. Cancer Immunol Immunother 2011; 60(10): 14611472

97. Diken M, Kreiter S, Vascotto F, Selmi A, Attig S, Diekmann J, Huber C, Türeci Ö, Sahin U. mTOR inhibition improves antitumor effects of vaccination with antigen-encoding RNA. Cancer Immunol Res 2013; 1(6): 386-392

98. Mineharu Y, Kamran N, Lowenstein PR, Castro MG. Blockade of mTOR signaling via rapamycin combined with immunotherapy augments antiglioma cytotoxic and memory T-cell functions. Mol Cancer Ther 2014; 13(12): 3024-3036

99. Moore EC, Cash HA, Caruso AM, Uppaluri R, Hodge JW, Van Waes C, Allen CT. Enhanced tumor control with combination mTOR and PD-L1 inhibition in syngeneic oral cavity cancers. Cancer Immunol Res 2016; 4(7): 611-620 